\title{
Optimal timing of operation for bleeding peptic ulcer: prospective randomised trial
}

\author{
D L MORRIS, P C HAWKER, S BREARLEY, M SIMMS, P W DYKES, M R B KEIGHLEY
}

\begin{abstract}
From October 1980 to September 1983 all patients with upper gastrointestinal bleeding were admitted to a centralised unit and investigated by early endoscopy. A total of 142 patients with a proved duodenal or gastric ulcer were randomised after stratification for age and site of ulcer to early (aggressive) surgical management or a delayed (conservative) policy. Significantly more operations $(n=42 ; 60 \%)$ were performed in the early than in the delayed $(n=9 ; 20 \%)$ groups $(p<0.01)$. There were no deaths among the 42 patients under 60 .

The overall mortality in the 100 patients aged over 60 was $10 \%$ and when analysed on an "intention to treat" basis there was no difference between early and delayed surgery. When, however, an unrelated death from a bleeding colonic polyp was excluded and the data analysed on "treatment received" the mortality was only $2 \%$ in the early group compared with $13 \%$ in the delayed group $(\mathbf{p}<0.05)$. When analysis was confined to gastric ulcer the difference between early $(0 \%)$ and delayed $(24 \%)$ treatment was even greater.
\end{abstract}

The results of this trial indicate that for patients over 60 an aggressive surgical policy is associated with a significant reduction in mortality.

The General Hospital, Birmingham B4 6NH

D L MORRIS, MD, FRCS, lecturer in surgery

P C HAWKER, MD, MRCP, senior registrar in medicine

$S$ BREARLEY, FRCS, surgical research fellow

$M$ SIMMS, FRCS, lecturer in surgery

P W DYKES, MD, FRCP, consultant physician

M R B KEIGHLEY, MS, FRCS, consultant surgeon and reader in surgery

Correspondence to: Mr D L Morris, Department of Surgery, University Hospital, Nottingham.

\section{Introduction}

Despite improvements in diagnostic techniques and increasing surveillance of patients the reported mortality rate from bleeding peptic ulcer has remained relatively unchanged over the past 30 years, although the increasing proportion of high risk elderly patients presenting with bleeding peptic ulcer may be masking a real improvement in results. This increase poses important questions concerning the appropriate management policy. The role of surgery in management of bleeding peptic ulcersespecially in high risk elderly patients-has long been controversial. ${ }^{2}$ There are two opposing views. The first is that an aggressive policy of investigation and early surgical intervention may reduce the mortality consequent on rebleeding, and three groups advocating this policy have reported a mortality of less than $5 \%$ in bleeding peptic ulcers. ${ }^{3-6}$ Other workers, however, point to a high postoperative mortality rate and suggest that careful monitoring and delayed surgery may reduce postoperative deaths and thus overall mortality. ${ }^{7-9}$

The nature of an aggressive or delayed policy has often not been clearly defined and to date there have been no randomised controlled trials comparing these approaches. Since 1980 all patients presenting to the General Hospital, Birmingham, with suspected upper gastrointestinal haemorrhage have been admitted to a central gastrointestinal unit for investigation and management supervised by a small combined medical and surgical team. This centralisation provided an excellent opportunity to define and compare an aggressive (early) with a conservative (delayed) surgical policy in management of bleeding peptic ulcers.

\section{Method}

From October 1980 to September 1983 all patients admitted to this hospital with upper gastrointestinal bleeding, or who bled while in hospital, were seen and assessed by a member of the gastrointestinal 
bleeding team and transferred to a designated area on our gastrointestinal ward. After resuscitation the patient was examined by endoscopy under diazepam sedation in an endoscopy suite using an Olympus $2 \mathrm{~T}$ or an ACM Tx82 twin channel endoscope. Most endoscopies were carried out within 12 hours, but for patients with major haemorrhage endoscopy was usually performed within six hours of admission. Only patients with a proved peptic ulcer were eligible for entry into the study.

Initially patients were excluded if there was more than one possible source of bleeding, if they were taking anticoagulants, if under the age of 25 , or if judged too ill to undergo operation. Specific consent was not obtained from patients, and this decision was accepted by the local ethical committee.

All patients received intravenous cimetidine $200 \mathrm{mg}$ six hourly until able to take $\mathbf{4 0 0} \mathrm{mg}$ by mouth twice daily. After endoscopy they were stratified for age (over 60, under 60) and site of ulcer (duodenal, gastric) and randomised by sealed envelopes to either early (aggressive) or delayed (conservative) surgical management.

Operations were carried out once any one of the following strictly defined criteria was fulfilled.

Criteria for early group: 4 units blood or plasma expander required to correct acute blood loss in 24 hours; one rebleed; endoscopic stigmata (active bleeding, visible vessel, adherent clot, spots); previous upper gastrointestinal haemorrhage plus two year history of dyspepsia.

Criteria for delayed group: 8 units blood or plasma expander required to correct acute blood loss in 24 hours; two rebleeds in hospital; persistent bleeding requiring transfusion of 12 units in 48 hours or 16 units in 72 hours.

The volume and rate of blood transfusion were decided clinically. Central venous lines were not used except in patients with massive haemorrhage and in some after operation. Only blood or plasma expander given for the replacement of circulating blood volume was considered under the volume criteria, blood transfusions for anaemia being excluded.

Operations were performed or supervised by surgeons of at least senior registrar status. All patients undergoing operation were given heparin 5000 units subcutaneously twice daily for five days or until mobile and a single prophylactic dose of cefuroxime $1.5 \mathrm{~g}$ intravenously preoperatively. The type of operation was decided by the surgeon.

As a result of an interim analysis at 15 months (102 patients) those under 60 were excluded from further study. We also decided to exclude patients who had undergone previous gastric surgery, as many surgeons considered that further assessment of gastric secretion was essential to plan further surgery.

Statistical analysis of results was performed using the proportionate difference test.

Exclusions-Twenty five patients were excluded from the study. In six there were two possible sources of bleeding, five patients aged over 60 had undergone previous gastric surgery, and three were judged to be unfit for any surgery, one of whom died. Three patients had coexistent perforation and haemorrhage, and two died. Two patients with gastric ulcers were excluded as malignancy was suspected although subsequently excluded. One patient aged 100 years was not actively investigated. Two patients were referred late, and three patients were never referred for assessment. All 25 patients excluded from the study were followed up while in hospital and had an overall mortality of $12 \%$ (three deaths).

\section{Results}

One hundred and forty two patients (42 aged under 60, 100 aged over 60 ) were entered into the study and were evenly distributed between categories. The early and delayed groups in each category were well matched for age, sex, pulse, blood pressure, and haemoglobin concentration on admission (see tables I-IV).

Operations-A total of 57 patients $(40 \%)$ underwent operation, $59 \%$ of those in the early surgery group and $21 \%$ in the delayed group.

\section{PATIENTS AGED UNDER 60}

There were no deaths among the 42 patients aged under 60 . Only five patients had a gastric ulcer, of whom four were randomised to the early group and one to the delayed group. Three underwent operation (in the early group), but owing to small numbers these five patients were excluded from further analysis.

Of the 37 patients with duodenal ulcers, 19 were randomised to the early group and 18 to the delayed group (table I). The groups were closely similar for all prognostic features, but operation rates in the early $(47 \%)$ and delayed $(6 \%)$ groups were significantly different $(p<0.01)$. Indications for surgery in the early group were stigmata of haemorrhage (six cases), rebleeding (three), volume replaced (two), and presence of two criteria (two). The only operation in the delayed group was carried out for a second rebleed. In the face of such a high operation rate in the early group, a low rebleeding rate, and no deaths an aggressive surgical policy seemed unjustified for patients under 60 , and after 15 months of this three year study such patients were excluded.

\section{PATIENTS AGED OVER 60}

One hundred patients aged 60 or over were randomised to early or delayed management. There were 20 with gastric ulcer and 28 with duodenal ulcer in the early group compared with 20 with gastric ulcer and 32 with duodenal ulcer in the delayed group. The patients in each group were similar with regard to the principal prognostic features (tables II and III).

Of the elderly patients with duodenal ulcer, 17 randomised to early surgery required operation. Of these, 14 had endoscopic stigmata, eight fulfilled blood volume requirements, three rebled, two had a previous history, and three fulfilled two or more criteria. Of the patients with duodenal ulcer treated by the delayed policy, nine underwent surgery, eight for the second rebleed and one for volume requirements.

In the early group 13 of the patients with gastric ulcer required surgery. Again stigmata of haemorrhage were the most common

TABLE I-Patients with duodenal ulcer under 60 years of age

\begin{tabular}{|c|c|c|}
\hline & $\begin{array}{c}\text { Early } \\
(n=19)\end{array}$ & $\begin{array}{l}\text { Delayed } \\
(n=18)\end{array}$ \\
\hline $\begin{array}{l}\text { Mean age (years) }(\mathrm{SD}) \\
\text { No with pulse rate }>100 / \mathrm{min}^{*} \\
\text { Mean pulse rate/min }(\mathrm{SD})^{*} \\
\text { No with systolic blood pressure }<100 \mathrm{~mm} \mathrm{Hg} \\
\text { Mean systolic blood pressure }(\mathrm{mm} \mathrm{Hg})(\mathrm{SD})^{*} \\
\text { Mean haemoglobin }(\mathrm{g} / \mathrm{dl})(\mathrm{SD})^{*} \\
\text { Mean units of blood transfused (SD) } \\
\text { No not transfused } \\
\text { No (\%) given operation } \\
\text { No of deaths }\end{array}$ & $\begin{array}{l}46 \cdot 1 \quad(9 \cdot 8) \\
6 \\
91 \cdot 1(20) \\
3 \cdot 1(25) \\
129 \cdot 1(25) \\
11 \cdot 8(3) \\
2 \cdot 6 \quad(2) \\
5 \\
9(47) \\
0\end{array}$ & $\begin{array}{cc}42 \cdot 8 & (12 \cdot 0) \\
10 & \\
99 \cdot 8 & (17) \\
2 & \\
125 \cdot 3 & (13) \\
11 \cdot 2 & (3) \\
3 \cdot 0 & (3) \\
4 & \\
1 & (6) \\
0 & \end{array}$ \\
\hline
\end{tabular}

*On admission.

TABLE II-Patients with duodenal ulcer over 60 years of age

\begin{tabular}{|c|c|c|}
\hline & $\begin{array}{c}\text { Early } \\
(\mathbf{n}=28)\end{array}$ & $\begin{array}{l}\text { Delayed } \\
(n=32)\end{array}$ \\
\hline $\begin{array}{l}\text { Mean age (years) }(\mathrm{SD}) \\
\text { No with pulse rate }>100 / \mathrm{min}^{*} \\
\text { Mean pulse rate/min }(\mathrm{SD})^{*} \\
\text { No with systolic blood pressure }<100 \mathrm{~mm} \mathrm{Hg} \\
\text { Mean systolic blood pressure }(\mathrm{mm} \mathrm{Hg})(\mathrm{SD})^{*} \\
\text { Mean haemoglobin }(\mathrm{g} / \mathrm{dl})(\mathrm{SD})^{*} \\
\text { Mean units of blood transfused (SD) } \\
\text { No not transfused } \\
\text { No (\%) given operation } \\
\text { No of deaths }\end{array}$ & $\begin{array}{l}71 \cdot 3(8) \\
10 \\
89 \cdot 8(21) \\
7 \\
122(31) \\
9 \cdot 3(3 \cdot 0) \\
4 \cdot 1 \quad(3) \\
6 \quad(61) \\
17 \\
2 \dagger\end{array}$ & $\begin{array}{l}70 \cdot 5(7) \\
14 \\
96 \cdot 2(17) \\
10 \\
125(31) \\
10 \cdot 0(2 \cdot 5) \\
5 \cdot 7(6) \\
5 \\
9 \quad(28) \\
3\end{array}$ \\
\hline
\end{tabular}

*On admission.

†One unrelated, due to bleeding colonic polyp.

TABLE III-Patients with gastric ulcer over 60 years of age

\begin{tabular}{|c|c|c|}
\hline & $\begin{array}{c}\text { Early } \\
(\mathbf{n}=20)\end{array}$ & $\begin{array}{l}\text { Delayed } \\
(\mathbf{n}=20)\end{array}$ \\
\hline $\begin{array}{l}\text { Mean age (years) }(\mathrm{SD}) \\
\text { No with pulse rate }>100 / \mathrm{min}^{*} \\
\text { Mean pulse rate/min }(\mathrm{SD})^{*} \\
\text { No with systolic blood pressure }<100 \mathrm{~mm} \mathrm{Hg} \\
\text { Mean systolic blood pressure (mm Hg) }(\mathrm{SD})^{*} \\
\text { Mean haemoglobin (g/dl) (SD) } \\
\text { Mean units of blood transfused (SD) } \\
\text { No not transfused } \\
\text { No (\%) given operation } \\
\text { No of deaths }\end{array}$ & 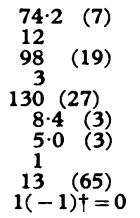 & $\begin{array}{c}72 \cdot 2(5) \\
6 \\
94 \quad(18) \\
3 \\
126(27) \\
9 \cdot 2(2) \\
5 \cdot 3(3) \\
1 \quad(25) \\
5 \quad(+1)+=5\end{array}$ \\
\hline
\end{tabular}

* On admission.

* On admission.
+ Randomised to early but treated as delayed. 
TABLE IV-Operative rate in management groups (treatment allocated)

\begin{tabular}{|c|c|c|c|c|}
\hline \multirow[b]{2}{*}{ Diagnosis } & \multicolumn{2}{|c|}{ Early } & \multicolumn{2}{|c|}{ Delayed } \\
\hline & $\begin{array}{l}\text { Operation } \\
\text { rate }\left({ }^{\circ},{ }_{1}\right)\end{array}$ & $\begin{array}{l}\text { Postoperative } \\
\text { deaths }\end{array}$ & $\begin{array}{l}\text { Operation } \\
\text { rate }\left("{ }_{0}\right)\end{array}$ & $\begin{array}{l}\text { Postoperative } \\
\text { deaths }\end{array}$ \\
\hline $\begin{array}{l}\text { Duodenal ulcer } \\
\text { Gastric ulcer }\end{array}$ & $\begin{array}{l}9 / 19(47) \\
3 / 4(75)\end{array}$ & $\begin{array}{c}\text { Age } 60 \text { years } \\
0 \\
0\end{array}$ & $\begin{array}{ll}1 / 18 & (6) \\
0 / 1 & (0)\end{array}$ & $\begin{array}{l}0 \\
0\end{array}$ \\
\hline Total & $12 / 23(52)$ & 0 & $1 / 19 \quad(5)$ & 0 \\
\hline $\begin{array}{l}\text { Duodenal ulcer } \\
\text { Gastric ulcer }\end{array}$ & $\begin{array}{l}1728(61) \\
13 / 20(65)\end{array}$ & $\begin{array}{c}\text { Age } 60 \text { years } \\
1 \\
1\end{array}$ & $\begin{array}{l}9 / 32(28) \\
5 / 20(25)\end{array}$ & $\begin{array}{l}3 \\
3\end{array}$ \\
\hline Total & $30 / 48(62)$ & 2 & $14 / 52(27)$ & 6 \\
\hline Overall & $42 / 71(59)$ & 2 & $1571(21)$ & 6 \\
\hline
\end{tabular}

TABLE V-Analysis of mortality in patients voer 60 years of age

\begin{tabular}{|c|c|c|c|c|c|c|c|c|}
\hline & \multicolumn{4}{|c|}{ Treatment received } & \multicolumn{4}{|c|}{ Intention to treat } \\
\hline & \multirow{2}{*}{$\begin{array}{l}\text { No } \\
\text { of } \\
\text { cases }\end{array}$} & \multicolumn{2}{|c|}{ Deaths } & \multirow{2}{*}{$\mathrm{p}$} & \multirow{2}{*}{$\begin{array}{c}\text { No } \\
\text { of } \\
\text { cases }\end{array}$} & \multicolumn{2}{|c|}{ Deaths } & \multirow{2}{*}{$p$} \\
\hline & & No & $\%$ & & & No & $\%$ & \\
\hline $\begin{array}{l}\text { Duodenal } \\
\text { ulcer }\end{array}\left\{\begin{array}{l}\text { Early } \\
\text { Delayed }\end{array}\right.$ & $\begin{array}{l}28 \\
32\end{array}$ & $2^{*}$ & $\begin{array}{l}7 \\
9\end{array}$ & $\begin{array}{l}\text { NS } \\
\text { NS }\end{array}$ & $\begin{array}{l}28 \\
32\end{array}$ & $2^{*}$ & $\begin{array}{l}7 \\
9\end{array}$ & $\begin{array}{l}\text { NS } \\
\text { NS }\end{array}$ \\
\hline $\begin{aligned} \text { Gastric } & \text { Early } \\
\text { ulcer } & \text { Delayed }\end{aligned}$ & $\begin{array}{l}19 \\
21\end{array}$ & $\begin{array}{l}0 \\
5\end{array}$ & $\begin{array}{r}0 \\
24\end{array}$ & $\begin{array}{l}0.01 \\
0.01\end{array}$ & $\begin{array}{l}20 \\
20\end{array}$ & $\begin{array}{l}1 \\
4\end{array}$ & $\begin{array}{r}5 \\
20\end{array}$ & $\begin{array}{l}\text { NS } \\
\text { NS }\end{array}$ \\
\hline All ulcer $\left\{\begin{array}{l}\text { Early } \\
\text { Delayed }\end{array}\right.$ & $\begin{array}{l}47 \\
53\end{array}$ & $2^{*}$ & $\begin{array}{r}4 \\
15\end{array}$ & $\begin{array}{l}\text { NS } \\
\text { NS }\end{array}$ & $\begin{array}{l}48 \\
52\end{array}$ & $\begin{array}{l}3 \\
7\end{array}$ & $\begin{array}{r}6 \\
13\end{array}$ & NS \\
\hline
\end{tabular}

*Includes death from colonic polyp.

indication, ${ }^{10}$ together with volume replacement in four, rebleeding in three, and previous history in one; five fulfilled two or more criteria. In the delayed group five required surgery, three patients as a result of rebleeding and two on volume criteria.

\section{TYPE OF OPERATION}

Forty four patients with bleeding peptic ulcer underwent vagotomy, drainage, and underrunning of the ulcer, and four died (9\%). Eight Billroth I reconstructions were performed without mortality, but all four patients in whom a Polya type (three) or total (one) gastrectomy were carried out died. The overall operative mortality in this study (patients with duodenal ulcers and gastric ulcers combined) was 14 . $(8 / 57$; table IV). There was no operative mortality in patients under 60 ; of 44 patients over 60 who were given operations, however, $8\left(18^{\circ}\right)$ died. The operative mortality in the elderly was $7^{\circ}$ in the early group compared with $43^{\circ}{ }_{0}$ in those treated by the delayed policy $(\mathrm{p}<0.01)$.

\section{POSTOPERATIVE MORBIDITY}

Only one patient $(2 \%)$ developed wound infection, which was minor and due to Staphylococcus aureus. One patient was suspected of having a calf vein thrombosis, which was treated by compression bandaging alone, and none developed a pulmonary embolus. Wound dehiscence occurred in five patients, one of whom died. Fourteen patients developed postoperative respiratory complications and, although in most of these chest infections were minor, two died of respiratory failure.

\section{MORTALITY}

Overall mortality among all 142 patients in the study was $7^{\circ}$, (10 deaths; table $\mathrm{V}$ ). All of the deaths occurred in patients over 60 , so that the mortality rate in these patients was $10^{\circ}$

Analysis of mortality in patients over 60 on an intention to treat basis gave a rate of $6^{\circ}$ (three deaths) in the early group and a rate of $13 \%$ (seven deaths) in the delayed group (table V). One death, however, occurred in a patient randomised to early surgery in whom operation was not carried out until delayed criteria had been fulfilled. Analysed on a treatment received basis (table V), mortality in the early group was found to be $4^{\circ}$ (two deaths) and in the delayed group $15 \%$ (eight deaths) $(\mathrm{p}<0.05)$. Subsequent analysis is on the basis of treatment received. Both deaths in the early group occurred postoperatively in patients with duodenal ulcer. The first, in a 78 year old woman, occurred 18 days postoperatively as a result of bleeding from an infarcted colonic polyp, apparently unrelated to the operation. The second, in an 82 year old woman, resulted from peritonitis caused by a leak from a difficult pyloroplasty, which in retrospect should have been avoided.

There were five deaths in 21 patients with gastric ulcer treated by a policy of delayed surgery, as against none in 19 operated early $(\mathrm{p}<0.01)$.

The eight deaths in patients treated by a delayed policy were due to the following four major causes.

Death due to haemorrhage-Two patients, who would have qualified for surgery under the early criteria, died after second massive rebleeds before surgery could be undertaken. A third patient (aged 61) had a second massive, uncontrollable bleed and remained severely hypotensive during operation despite large volume transfusion. $\mathrm{He}$ developed irreversible postoperative renal failure and peritonitis from a leaking duodenal stump.

Postoperative cardiovascular disease-Two patients who suffered severe preoperative rebleeding died from cardiovascular complications. Both sustained a perioperative cerebrovascular accident and one was found to have a fresh myocardial infarction at necropsy. This patient appeared to have a series of strokes, each exacerbation coinciding with rebleeding and hypotension.

Postoperative respiratory deaths-Two patients died from postoperative respiratory complications. The first, aged 75 , suffered progressive respiratory failure despite ventilation, positive end expiratory pressure, and increasing inspired oxygen concentration. Histological changes compatible with hyaline membrane disease were found at necropsy. The second patient, aged 83, died from bronchopneumonia despite parenteral antibiotics and physiotherapy. Both patients had received large volume blood transfusions ( 10 and 8 units).

Other-One patient died probably from septicaemia after repair of an abdominal dehiscence.

\section{Discussion}

The heterogeneous composition of groups of patients with acute upper gastrointestinal haemorrhage makes overall mortality rates meaningless. Thus it is important in considering management policy to concentrate on definable groups, and our study re-emphasises that this implies not only pathological diagnosis but also age and other prognostic variables. Patients with portal hypertension, carcinoma, hiatus hernia, etc must clearly be examined separately, and peptic ulcer disease itself must be separated into gastric and duodenal ulceration; further sub-division must also be established according to age.

The present study has gone some way to answer the questions about optimal timing of surgery for bleeding ulceration, despite the very considerable difficulties in running a satisfactory scientific study. It was proposed in 1920 that an aggressive surgical policy was an essential part of safe management, ${ }^{2}$ and others have provided support for this approach with impressively low mortality figures (table VI). ${ }^{3-6}$ These results are better than other modern studies where this policy was not adopted, but comparison between reports is complicated by the different emphasis of each study. Ours is the first recorded attempt to mount a prospective randomised trial relating to this question

TABLE VI-Mortality rate for bleeding peptic ulcer in patients over 60 years of age

\begin{tabular}{|c|c|c|c|c|c|}
\hline Author & Year & Policy & $\begin{array}{l}\text { Operation } \\
\text { rate }\left({ }^{\circ} 0\right)\end{array}$ & $\begin{array}{c}\text { No of } \\
\text { patients }\end{array}$ & $\begin{array}{c}\text { Mortality } \\
\left(\begin{array}{l}0 \\
0\end{array}\right)\end{array}$ \\
\hline $\begin{array}{l}\text { Frankel and Truelove } \\
\text { Avery-Jones } \\
\text { Schiller } \text { et } a l^{112} \\
\text { Chang et al } \\
\text { Dronfield } \text { et } a l^{*}\end{array}$ & $\begin{array}{l}1955 \\
1956 \\
1970 \\
1977 \\
1979\end{array}$ & $\begin{array}{l}\text { Conservative } \\
\text { Conservative } \\
\text { Conservative } \\
\text { Aggressive } \\
\text { Conservative }\end{array}$ & $\begin{array}{l}16 \\
3 * \\
27 \\
57 \\
37\end{array}$ & $\begin{array}{r}56 \\
291 \\
597 \\
56 \\
188\end{array}$ & $\begin{array}{r}31 \\
16 \\
16 \\
4 \\
20\end{array}$ \\
\hline Present study & 1983 & $\left\{\begin{array}{l}\text { Early } \\
\text { Delayed }\end{array}\right.$ & $\begin{array}{l}59 \\
21\end{array}$ & $\begin{array}{l}47 \\
53\end{array}$ & $\begin{array}{r}4 \\
15\end{array}$ \\
\hline
\end{tabular}

*All cases. 
and was possible only because of centralised management of the patients and the close cooperation of seven medical and six surgical units in our hospital. Over three years these alternate policies have with few exceptions been maintained by good will and frequent internal reporting of results. We doubt, however, whether such consistent policies would be practicable on a multicentre basis which could provide larger numbers for statistical analysis. The number of medical staff required is a major limitation for adherence to a defined protocol.

The operation rate for the aggressive policy in younger patients was found to be unexpectedly high $(47 \%)$ at the time of the interim review. No deaths occurred and, as it is most unlikely that any significant difference in mortality could ever emerge, this section of the trial was terminated.

The most acceptable statistical analysis related to treatment allocated, but the data were also examined on the basis of treatment received. Although analysis on the basis of treatment allocated showed a strong trend in favour of early surgery for patients with gastric ulcer and the whole group, no statistically significant difference was present, and probably many more patients would be required for significance to be achieved. Analysis on the basis of treatment received did, however, show a significant difference $(p<0.01)$ favouring early surgery in the gastric ulcer group. Furthermore, when the death from postoperative bleeding from a colonic polyp was excluded from the early group a significant difference $(p<0.05)$ was achieved overall. Mortality in elderly patients with duodenal ulcer was more evenly balanced, although there were still relatively more deaths in the delayed group.

Examination of the causes of death left us apprehensive about the ethical advisability of continuing this study. Deaths in the delayed group were all of the type seen when we examined this problem previously ${ }^{7}$ and related to massive bleeding, sepsis, and cardiovascular and respiratory complications. Central venous lines were used in the most severely ill, and every effort was made to keep up with the rate of bleeding. Despite this three deaths were directly related to exsanguination, two to myocardial or cerebral ischaemia, and two to respiratory complications in patients receiving large volumes of blood. Of the three elderly patients who died having drawn early surgery, one was in fact treated as delayed and died from respiratory complications. The other two deaths were both associated with errors of judgment and should have been avoided.

Examined from the viewpoint of operative mortality, the evidence is again in favour of the safety of early surgery in the elderly. Among the patients over 60 overall operative mortality for early surgery was $7 \%(2 / 30)$ and for late surgery $43 \%(6 / 14)$. The high level of wound dehiscence is accepted as a surgeon related technical failure but was possibly related to the large number of elderly and malnourished patients in this study. All four patients who underwent gastric resections other than a Billroth I gastrectomy died, but this reflected the advanced nature of their disease rather than the choice of a particular operation.

The apparent relation between mortality and exsanguination might suggest a disastrous mortality rate, and yet for patients over 60 treated by a policy of delayed surgery this still reached only $15 \%$, which is comparable with the figure in other studies

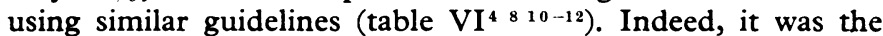
mortality of the early surgery group of the over 60 s which was impressive (table VI) $(4 \%$ ) and again compares well with the other study of older patients treated by an aggressive approach. ${ }^{4}$ Hence we do not accept that an aggressive policy in the elderly carries an unnecessary surgical risk and believe that there is now sufficient evidence to take the reverse view-even in patients seriously ill with other coincident disease. We have therefore adopted the aggressive policy detailed in this study as the standard for patients over 60 , and the control groups of future planned studies of other therapeutic modalities will be compared against these data. It is slightly incongruous that we must conclude quite the reverse for younger patients, where an aggressive policy led to an unnecessarily high operation rate with no apparent benefit.

We are most grateful to ACM for the loan of endoscopic equipment, to the General Hospital Bicentenary Fund for financial support, and to all physicians, surgeons, and staff of the General Hospital, Birmingham, for allowing us to study their patients. We also thank Dr J A Waterhouse and Mrs C Roginski, of the Regional Cancer Registry, for advice and help with statistical methods. Finally, we are grateful to Sister A Glover and the staff of the endoscopy unit and gastrointestinal ward.

\section{References}

${ }^{1}$ Kronlien RU. Ueber die chirurgische behandlung des magengeschwurs. Arch P Klin Chir 1906;79:644-66.

2 Finsterer H. Surgical treatment of acute profuse gastric hemorrhage. Surg Gynecol Obstet 1939;69:291-8.

3 Palmer ED. The vigorous diagnostic approach to upper gastrointestinal tract hemorrhage-a 23 year prospective study of 1400 patients. F $A M A$ A $1969 ; 207: 1477-80$.

' Chang F, Drake JE, Farkes GJ. Massive gastrointestinal hemorrhage in the elderly. Am f Surg 1977;134:721-3.

${ }^{5}$ Hunt PS, Hansky J, Kormon MG. Mortality in patients with haematemesis and melaena-a prospective study. $B r \operatorname{Med} \mathcal{F} 1979 ; \mathrm{i}: 1238-40$

${ }^{6}$ Hellers G, Ihre T. Impact of change to early diagnosis and surgery in major upper gastrointestinal bleeding. Lancet 1975; ii:1250-1.

7 Allan RN, Dykes PW. A study of factors influencing mortality rates from gastrointestinal haemorrhage. $Q \mathcal{F}$ Med 1976;180:533-50.

$\checkmark$ Dronfield MW, Atkinson M, Langman MJS. Effect of different operative policies on mortality from bleeding peptic ulcer. Lancet 1979;i :1126-8.

${ }^{9}$ Vellacott KD, Dronfield MW, Atkinson M, Langman MJS. Comparison of surgical and medical management of bleeding peptic ulcers. Br Med $\mathcal{F}$ $1982 ; 284: 548-50$.

${ }^{10}$ Frankel GJ, Truelove SC. Haematemesis and melaena with special reference to peptic ulcer. Br Med J 1955 ; : $999-1002$.

11 Avery-Jones F. Hematemesis with special reference to causation and the factors influencing the mortality from bleeding peptic ulcers. Gastroenterology 1956;30:166-90.

12 Schiller KFR, Truelove SC, Gwyn Williams D. Haematemesis and melaena with special reference to factors influencing the outcome. Br Med f 1970;ii:7-14.

(Accepted 8 February 1984)

What treatment, if any, is advised for an elderly woman with osteoporosis who had a mastectomy for breast carcinoma 30 years ago with a recent recurrence at the scar site?

This patient has a slow growing carcinoma, which may not necessarily shorten her life. Treatment of her osteoporosis is required only if the condition is progressive with episodes of back pain due to recurrent vertebral collapse. Oestrogens, although effective in arresting the progress of this disorder, are contraindicated in this case. The safest regimen would be the use of supplemental calcium 800-1200 ng daily (Sandocal two to three tablets). Studies in Leeds have shown that this is almost as effective as regimens that include oestrogens in arresting bone loss as assessed by serial measurements of height and of metacarpal cortical area. ${ }^{1}$ Small doses of vitamin D should be added only if the patient lacks exposure to sunlight owing to limitation of outdoors activity. An alternative regimen is to combine supplemental calcium with an anabolic steroid such as Stanozolol ( $5 \mathrm{mg}$ daily). This treatment of osteoporosis has been shown to increase total bone mass when the total body calcium is determined by neutron activation analysis. ${ }^{2}$ The results of recently reported studies conducted at the Mayo Clinic show that the addition of sodium fluoride $(50 \mathrm{mg}$ daily) confers further benefits in reducing the frequency of fractures in osteoporotic subjects, but the high incidence of toxic effects makes its routine use unjustifiable. ${ }^{3}$ - A N EXTON-SMITH, Barlow professor of geriatric medicine, London.

${ }^{1}$ Nordin BEC. Calcium metabolism and bone. In: Exton-Smith AN, Caird FI, eds Metabolic and nutritional disorders of the elderly. Bristol: Wright, 1980

Chestnut CH, Ivey JL, Nelp WB, Baylink DJ. Assessment of anabolic steroids and calcitonin in the treatment of osteoporosis. In: Barzel US, ed. Osteoporosis II. New York: Grune and Stratton, 1979.

${ }^{3}$ Riggs BL, Seeman E, Hodgson S, Taves DR, O'Fallon WM. Effects of the vertebral fracture occurrence in postmenopausal osteoporosis. N Engl 7 Med 1982;306:446-50. 